\title{
DEVELOPMENT OF MOBILE RADIO COMMUNICATIONS- THE "WORK-HORSE" RADIO SERVICES
}

\author{
Jeremiah Courtney* and Arthur Blooston $†$
}

Radio communications are associated in most people's minds with broadcastingthe "glamour girl" among the many radio services administered by the Federal Communications Commission. This is not unnatural in view of the popularity of the aural and visual media of communications and entertainment; their impact upon public opinion; and the broadcasters' not inconsiderable influence in the halls of Congress. But the world of radio communications neither begins nor ends with broadcasting. Equally important to our economic life and national security, though much less publicized and glamorized, are the mobile services of virtually infinite variety which more and more help the wheels of our complex economy to turn smoothly.

These mobile radio services may best be described as the "work-horse" radio services. They are: the police and fire radio services, which enable cruising police cars and fire trucks to be in constant communication with their respective headquarters; the industrial radio services, which permit the managers of industrial enterprises, building contractors, power utilities, oil companies, etc., to maintain contact with and control over widely-dispersed vehicles; the land transportation radio services, which provide similar control over and contact with trucks engaged in the pickup and delivery of property, interstate busses, and taxicabs cruising the city streets; the marine and aviation radio services, which supply safety communications for ships at sea and aircraft in the air; and the common-carrier mobile services, which provide communications for hire to the public. Each service is governed by a set of regulations which prescribe who may hold an authorization and how it may be used after it is issued by the FCC. ${ }^{1}$

* A.B. 1932, LL.B. 1935, Columbia University. Member of the District of Columbia and New York bars. Formerly Assistant General Counsel, Federal Communications Commission.

TLL.B. 1948, University of Minnesota, LL.M. 1952, University of Chicago. Member of the District of Columbia, Illinois, and Minnesota bars. Formerly attorney, Federal Communications Commission. The authors are associated in the practice of law in Washington, D. C., specializing in mobile and point-to-point radio communications matters.

${ }^{1}$ The mobile radio services are governed by the regulations promulgated by the Federal Communications Commission under the authority of $\$ 303$ of the Communications Act of 1934, as amended, 48 STAT. 1082 (1934), 47 U.S.C. $\$ 303$ (1952). Specifically, these services are: Part 7, Stations on Land in the Maritime Services; Part 8, Stations on Shipboard in the Maritime Services; Part 9, Aviation Services; Part Io, Public Safety Radio Services; Part II, Industrial Radio Services; Part I4, Public Fixed Stations and Stations of the Maritime Services in Alaska; Part 16, Land Transportation Radio Services; Part Iq, Citizens Radio Service; and Part 21, Domestic Public Radio Services. 47 C.F.R. $\$$ 7.1, 8.I, 9.I, 10.I, II.I, I4.I, 16.I, I9.I, and 21.I, et seq., respectively (Supp. 1956); I Pixe \& Fischer Radio ReG. II 57.I, 58.I, 59.I, 60.I, 6I.I, 64.I, 66.I, 69.I, and 7r.I et seq., respectively [hereinafter cited as R.R.]. 


\section{INTRODUCTION}

Mobile radio communications fall into two broad categories: (I) private radio communications, i.e., radio communications used by persons or corporations in their own businesses for their own purposes; and (2) common-carrier communications, i.e., systems operated by common carriers offering facilities for hire to the public at large. 2 The function of mobile communications, however, whether provided through a private system for a company's own use or purchased from a common carrier, is the same: to control and coordinate the movement of dispersed vehicles with maximum efficiency. The high cost of labor and vehicular equipment makes it imperative for every enterprise to have as close control as possible over the vehicles operated out of the sight of the management. Those of us who labor in the mobile communications vineyard are firmly convinced that the time is not too far distant when every commercial vehicle will be radio-equipped.

The reasons for this conclusion will appear from an analysis of the significance of mobile communications to management generally. The primary function of the managers of any enterprise is the projection of themselves to the greatest extent possible into every important part of the industrial or commercial process. This has been true from the earliest times in man's productive activities. The one-man farm was operated ideally by the owner because he had direct control of the whole operation. When he engaged a hired hand to share the work and increase the productivity of his farm, he became a manager. As such, his problem was to get the work of the hired hand done as he would do it himself. The solution for him was easy: oral instructions, which could be altered quickly during the day as required. Now, a manager often is responsible for instructing and supervising hundreds of employees, but his basic problem in directing a force remains with him-he must still try to get the work done essentially as he would do it himself or as he would wish it done, even though it is physically impossible for him directly to oversee all parts of the operation.

The difficulties of the problem are intensified in modern industry when operational areas are large and scattered and production procedures are complex and interdependent. Rapid communication is an important element in overcoming the difficulties. Through the years, many well-known and efficient transmitting methods have been developed, and industry has made full use of the telegraph and the telephone and other fixed wire-line facilities. Radio, however, is used when wire-lines cannot be used at all, as in the operation of mobile vehicles, from which it is obviously impossible to trail wires; it is also used in certain kinds of operations where wire-

${ }^{3}$ Parts Io, II, I6, and $x_{9}$ are solely private services; Parts $7,8,9$ and $I_{4}$ are primarily private services, but they contain certain provisions for the rendition of common-carrier communications aboard ships, aircraft, and by coast stations; Part $2 \mathrm{I}$ is solely a common-carrier service. Each of these services, except the citizens radio service, is, in turn, subdivided into several component services. For example, industrial radio services, consists of eight specific services as follows: power radio service, petroleum radio service, forest products radio service, motion picture radio service, relay press radio service, special industrial radio service, low power industrial radio service, and industrial radio-location service. 
lines would be cumbersome or hazardous, or uneconomical, and in the activities of mobile working crews in locations where only a portable communications system is feasible or desirable. In all those cases, radio communication permits more effective disposition of vehicles and personnel, which in turn results in substantial conservation of machine-hours, man-hours, and vehicle-hours-or, in short, lower costs of production. Here lies the strength and future of mobile radio communications.

Although the functions of private and common-carrier mobile communications are identical, the operating rights of these two categories of uses of the radio spectrum are vastly dissimilar. Common-carrier frequency assignments are rigidly protected by regulations against interference and common carrier licensees appear now in the process of receiving a degree of protection against economic injury as well. ${ }^{3}$ Thus, each applicant for and licensee of a mobile common-carrier system receives an exclusive frequency assignment and is assured that no one else will be able to use this frequency within his protected area of operation. This area is defined by the Rules as that delineated by a field strength contour of 37 decibels above one microvolt per meter. ${ }^{4}$ The size of the protected area depends upon the power of the base station, the antenna height, and the configuration of the terrain. The protected contour usually covers a radius of 15 to 30 miles around the base station, although greater coverages are not uncommon.

No private radio system licensee receives like protection from interference, even though his equipment investment may be, and often is, many times greater than that of a two-way common-carrier operator and is employed to control a very much larger capital investment. For frequencies in the private radio services are available on a shared basis only. The Rules governing the various private services uniformly provide that no frequencies will be assigned to the exclusive use of any one applicant. ${ }^{.}$ The only recognition the Commission's Rules give to the protection problem inherent in frequency sharing is the requirement honored more in breach than observance that applicants and licensees must cooperate in the selection and use of frequencies. ${ }^{\circ}$ The Commission itself does not consider a failure to comply with this requirement as a disqualifying factor or a reason for not assigning the frequency requested. ${ }^{7}$ In several services, there are functioning industry frequency coordinating committees whose recommendations as to the frequency selection for any given applicant are

${ }^{3}$ See pages $638-42$ infra.

47 C.F.R. $\$ 21.504$ (Supp. 1956).

84 C.F.R. $\$ \$$ Io.101, Ir.8, and I6.8 (Supp. 1956); I R.R. 9960.101 , 61.8, and 66.8 (1956).

'Ibid.

'See In re Application of Royal Cab Co., 13 R.R. 449, 455 (1955): "It is, of course, true that the applicant, prior to the filing of its application, had not attempted to coordinate its frequency with other users in the area, and the Commission has previously so found. The Commission has never held, however, that such a failure entails an absolute disqualifying of the applicant to be a licensee of the Commission." In fact, it does not even entail a relative disqualification, since the Commission, particularly in its largest industrial radio service, the special industrial radio service, will assign any frequency requested by the applicant (and available under the Rules) without any questions asked, and regardless of any conflict with other users. 
although advisory in nature, as a practical matter, followed by the Commission. This provides a rather imperfect means of coordinating the initial frequency selection, but does not eliminate frequency sharing and the problems that result therefrom in areas of frequency congestion.

\section{II}

\section{Allocating the Radio Spectrum}

The principal reason for not protecting the frequency assignments in the private radio services appears to be the paucity of frequencies available to these services due to the existing imbalance between Government and non-Government allocations on the one hand, and the allocations to the broadcast services and the mobile services on the other hand. This, according to the FCC, makes it administratively impracticable to assign the small number of available mobile frequencies to a large number of applicants on any other but a shared basis and under an assembly line application-processing procedure. In fact, however, this should be the very reason for extra care in assignments to insure that those applicants who must have radio communications in their businesses are not deprived of this modern tool because of interference from others using the same frequency.

The jurisdiction of the FCC is limited to non-Government stations. Stations operated by the United States Government receive their frequency assignments from the President ${ }^{8}$ who discharges this function through the Inter-Department Radio Advisory Committee, known in Washington as IRAC. Under this dual system of frequency assignments, both the FCC and IRAC enjoy equal and plenary authority over the entire frequency spectrum. Since each could assign the entire spectrum, it is not difficult to understand why, with that bludgeon in the hand of each, they have both agreed that the usable radio spectrum ${ }^{9}$ should be divided equally between the Government and other users, as it approximately now is. While the frequency allocations and assignments made by the FCC are governed by the Rules available to anyone who cares to consult them and are a matter of record at the FCC offices in Washington, the use of the spectrum by the Government is surrounded with a shroud of secrecy. Such secrecy naturally raises a question whether the Government is utilizing the scarce spectrum space efficiently. This question is particularly timely now that the Government is casting a covetous eye on television channels 2-6, to the great alarm of the broadcast industry. ${ }^{10}$ 'The concern over the Government's use of the spectrum

${ }_{48}^{8}$ STAT. 1083 (1934), as amendéd, 47 U.S.C. $\$ 305$ (1952).

${ }^{\circ} 30,000 \mathrm{mc}$. is considered to be the limit of the usable spectrum under the present state of the radio art.

${ }^{10}$ Editorial, The Air Curtain, Broadcasting-Telecasting, Aug. 19, x957, p. r22; see also id., Aug. 26 , 1957, p. 48. This threat to television channels $2-6$ has been removed (after this article was written) at the expense of the private radio services by the Commission's Order dated Sept. 19, 1957, 22 FED. REG. 7636 (1957), which reallocated to the Government $400 \mathrm{kc}$. of space in each of the two very extensively used private mobile VHF bands, $46.6-47.0 \mathrm{mc}$. and $49.6-50.0 \mathrm{mc}$., with the result that the existing private users of these two bands will have to vacate them and find replacement frequencies. One of these bands, 49.6-50.0 mc., is one of the most heavily, if not the most heavily, occupied band, with a great concentration of important and large industrial mobile systems operating in it. 
space and its demand for more, gave rise to the introduction of two joint resolutions during the last session of Congress for the establishment of a commission whose functions would be to investigate the utilization of frequencies allocated to the federal government and to evaluate its present use and future needs. ${ }^{11}$

The FCC is under a statutory mandate contained in section $303(\mathrm{~g})$ of the Act to "study new uses for radio and generally encourage the larger and more effective use of radio in the public interest." As a result, however, of the excessive allocation of spectrum space heretofore made to the Broadcast Radio Services below rooo mc., ${ }^{12}$ the efforts of the present members of the FCC to accommodate the growing needs of the established industrial, public safety, and common-carrier uses of radio are severely hampered and the carrying out of the intent of section $303(\mathrm{~g})$ made increasingly more difficult.

The imbalance that exists today in broadcast and nonbroadcast allocations below rooo megacycles becomes apparent upon even the briefest comparison. Looking at the 935 megacycles of space located between 25 and $960 \mathrm{mc}$, we see 240 megacycles ${ }^{13}$ allocated to the Government. This leaves 695 megacycles for nongovernment uses. Of these 695 megacycles, 512, or nearly 74 per cent, are allocated to the exclusive use of TV and FM broadcasting; 62 megacycles, or nearly 9 per cent, are shared between broadcast and nonbroadcast services. For all other uses-industrial, commercial, transportation, public safety, common-carrier, and amateur-a scant 17 per cent. ${ }^{14}$

Further, in the most desirable lower portion of this band, below $420 \mathrm{mc}$. (the Government has no allocations between 420 and $960 \mathrm{mc}$.), where the broadcast share is not so large proportionately as in the upper part, the lion's share, 6r per cent, is taken up by the Government, leaving only 12 per cent for all the rest of the commercial, industrial, transportation, public safety, and common-carrier uses.

The favored treatment of the broadcast services does not end with the tremendous amount of critical spectrum space assigned to their uses. It is carried over to the channel width assignments and an apparent freedom from pressures to improve the techniques of broadcast communications with a view to conserving channel space.

The FM broadcast service, since its inception more than ten years ago, has been allowed to use channels $200 \mathrm{kc}$. wide in the precious $88-\mathrm{r} 08 \mathrm{mc}$. portion of the

${ }^{11}$ S. J. REs. I06, 85th Cong., Ist Sess. (I957), introduced by Senator Potter, and H. J. Res. 381, B5th Cong., rst Sess. (1957), introduced by Congressman Bray. No action has been taken on either resolution.

12 The upper limits of usefulness for mobile services, principally because of limited power supply and restricted antenna heights involved, has been considered to be approximately $500 \mathrm{mc}$, although one manufacturer has reported somewhat promising experimentation higher in the spectrum. Any. general reference to the frequencies below rooo mc. relates to the band $25-960 \mathrm{mc}$, which is the portion of the spectrum useful for mobile radio services and low cost point-to-point communication circuits. This is also the band in which the VHF and UHF television allocations are located, as well as the allocation for the FM broadcasting service.

${ }^{13}$ This figure is necessarily approximate because of the secrecy that surrounds the actual government assignments. Accordingly, in the three bands (108-32 mc., 328.6-35.4 mc., and 400-06 mc.) which are shared with non-Government users, the total space in these bands has been apportioned, for the purpose of these statistics, half to the Government and half to nongovernment users.

${ }^{14}$ The FCC's Table of Frequency Allocation is set out in 47 C.F.R. $\$ 2.104$ (I956); I R.R. \$ 52.104. 
spectrum. ${ }^{15}$ The television service, likewise from the beginning, has been allocated $6 \mathrm{mc}$. (6000 kc.!) wide channels in the two parts of the spectrum which that allocation Colossus bestrides. The width of each TV channel can best be illustrated by the fact that the whole AM radio broadcast service, consisting of 3000 stations, operates within a trifle more than I.o mc., i.e., one sixth of the space occupied by a single TV channel. There are 82 of these $6 \mathrm{mc}$. wide channels assigned to TV; 12 in the VHF portion of the spectrum and the remaining 70 in the UHF. ${ }^{16}$ These 82 channels which, according to the allocation plan, are designed to accommodate nearly 2100 TV stations ${ }^{\mathbf{1 7}}$ are less than 25 per cent utilized. The overallocation and underutilization of the television bands is thus no less pronounced than in the FM band, discussed in note ${ }_{5}$ supra. In the space designed for more than 2000 stations, there were operating as of August 3, I957, 503 television stations, of which 4I2 are in the VHF and $9 r$ in the UHF band. The spectrum waste entailed in reserving $420 \mathrm{mc}$. of space for less than I0o UHF TV transmitters requires no comment. There will be a handful of VHF stations added when the pending contested proceedings by which they are held up are concluded. As to new UHF stations, there are 138 construction permits outstanding, of which 40 have been on the air but went off; and 98 never commenced operating, with the overwhelming majority never even having started construction. It is doubtful whether a significant number of these UHF permittees will ever go on the air. With this overabundance of spectrum space, it is small wonder that the TV and FM services seem to have made no effort to improve their broadcasting techniques so as to operate on narrower channels. We certainly hear nothing about "splitting" TV or FM channels, to use the all too familiar term that describes the progress toward better spectrum use by the land mobile services. ${ }^{18}$

In the case of the nonbroadcast services, of course, the skimpiness of the allocated space makes constant search for improvement a necessity-a choice between strangula-

${ }^{16}$ The FM broadcast service has 20 megacycles of space in the heart of the most desirable part of the spectrum for mobile use, between 88 and 108 megacycles, where long-range mobile communications are possible without the devastating "skip" interference that is found throughout the $25-50 \mathrm{mc}$. mobile band. The FM broadcast allocations are admittedly less than $25 \%$ used by FM broadcasters. The actual percentage of use may indeed be much less than $25 \%$. One example will illustrate the waste of the FM spectrum space: In the state of Arizona there is one FM broadcast station occupying 200 of the 20,000 kc. of space assigned the FM broadcast service there. Yet, no other use can be made of the entire FM band in that state because of the rigidity of the Commission's allocation structure. For the means of utilizing the FM band to its full extent for industrial communications, without harming in any way the FM broadcast service, see the petition of National Association of Manufacturers, Committee on Manufacturers Radio Use, In the Matter of Geographic Assignment of Certain Frequencies Allocated to the FM Commercial Broadcast Service and Establishment of a Manufacturers Radio Service, filed with the FCC on Feb. 3, r955.

${ }^{10}$ The band $30 \mathrm{mc}-300 \mathrm{mc}$. is known as the VHF (very high frequency) band; the band $300-3000$ mc. is known as the UHF (ultra high frequency) band. The UHF television occupies seventy-six mc." wide channels between 470 and $890 \mathrm{mc}$.

${ }^{17}$ Sixth Report on Television Allocations, I R.R. pt. 3, para. 9r:60r et seq. passim (1952).

${ }^{18}$ Channel "splitting" is the popular term which means that the separations between assignable frequencies are reduced to provide more center frequencies available for assignment. Such reductions are made possible by improvements in transmitting and receiving equipments and transmission techniques. 
tion and survival. During the same period when FM and TV have been content to rest on their assigned "laurels," broad as they are, the mobile services have gone from I20 kc. channel equipment in the $152-62 \mathrm{mc}$. band to the present $60 \mathrm{kc}$. channeling, with $30 \mathrm{kc}$. and $15 \mathrm{kc}$. channeling a not too distant goal. ${ }^{19}$ In the $25-50 \mathrm{mc}$. band and 450-70 mc. band, equipment manufacturers have already been successful in cutting the channels in half, from $40 \mathrm{kc}$. to $20 \mathrm{kc}$. and roo kc. to $50 \mathrm{kc}$., respectively, and are marketing equipment to match.

The FCC is becoming increasingly aware of the need for more frequencies for private mobile radio communications, but it has not yet come fully to appreciate the importance of such communications to the nation's economy. This is manifested in the Commission's desire to squeeze more frequencies out of the spectrum space allocated for mobile communications. The word "squeeze" is used advisedly. For this is precisely what the Commission is doing in a series of rule-making proceedings now in progress proposing to reduce the channel separations between the assignable frequencies in the 152-74 and 450-70 mc. bands and thus approximately to double the number of available frequencies. ${ }^{20}$ This proposal is, however, accompanied by a plan to enlarge the eligibility provisions so that every person will be able to obtain a license for a mobile station. ${ }^{21}$ By so doing the Commission will flood the many highly essential, established radio systems with new, often much less essential, licensees and magnify the frequency-sharing problem out of all proportion to the existing, difficult situation. Thus, while the FCC is recognizing the need for more frequencies for mobile communications, which is predicated on their importance in our economy, it is failing to recognize that this very importance demands that the communications which the Commission makes available be also useful for the purpose for which intended, i.e., the need for protecting the frequency assignments against becoming useless through excessive sharing.

The need for more frequencies and for protection of frequency usage are two of the most pressing problems in the mobile radio field, both private and commoncarrier. More frequencies would simplify the protection problem and even lessen the pressure to provide protection. But the answer does not lie in trying to squecze more frequencies out of the inadequate mobile allocation ${ }^{22}$-a technique which requires expensive shifts and adjustments for existing licensees-but in obtaining more space from those services which have an overly generous allocation and do not fully use it. Perhaps the first step in that direction has been taken when the Commission on April 5, 1957 adopted an Order of Inquiry initiating an investigation into

${ }^{10}$ See the proceedings listed in note 20 , infra.

${ }^{20}$ Notices of Proposed Rule Making in Docket No. Ir990, 22 Fed. REg. 2584 (1957); II991, id, at 2593; $x 1992, i d$. at 2602; $11993, i d$ at $2604 ; 11194, i d$. at 2606; and 11995 , id. at 2613 .

${ }_{21}$ See, e.g., Proposal to Create a Business Radio Service, in Docket No. I1991, supra note 20.

22 The industrial and land transportation radio services, which are the most rapidly growing private scrvices and the ones suffering most from frequency congestions and shortages, have frequencies in threc separate portions of the spectrum: 25-50 mc; 152-62 mc; and 450-60 mc. Each scrvice has a comparatively small number of frequencies in each of these bands. Some frequencies are allocated exclusively to one service and assignable, on a shared basis, to applicants in that service only; other frequencics are allocated on a shared basis with two or more services. 
the utilization of the radio spectrum between 25 and $890 \mathrm{mc}^{23}$ It is not likely, however, that this proceeding will be concluded soon enough to provide immediate relief. Meanwhile, others means of protection must be found. Fortunately, the protection problem appears to be susceptible of a more immediate solution, if the FCC is willing to act.

\section{III}

\section{Protection of Frequencies}

Protection in the private radio field in which radio communications are a tool in the licensee's business, such as manufacturing, road-building, trucking, etc., relates to the safeguarding of the radio equipment investment against uselessness which results from another person's operation on the same frequency, thereby seriously diminishing the value of the radio communications to the first user. The total investment in radio equipment used for private communications purposes is estimated to exceed half a billion dollars. ${ }^{24}$ There are many individual licensees in the petroleum, public utility, and other fields, whose radio equipment investment is in the hundreds of thousands of dollars-in several cases exceeding \$1,000,000. When a business concern decides to invest that much money in radio communications for which a federal franchise is required, it has the right to expect, and should be assured, a degree of protection not only because of the magnitude of the equipment investment, but also because radio greatly contributes to the efficiency of the industrial operations in which employed. While no definite figures are available, and it probably would be very difficult accurately to attribute the exact percentage of any increase in efficiency to radio communications, it is estimated that a road-building contractor, for example, is able to save ten per cent of its operating costs by using radio communications for dispatching its vehicles; ${ }^{25}$ one company which supplies specialized equipment and services to the petroleum drilling industry estimates that radio communications increase its efficiency by 15 per cent, while another company in the same type of business estimates that such communications give it the equivalent of one additional vehicle for each four employed; ${ }^{26}$ and, in the trucking field, "IO radio equipped trucks can do the work of 12 to 13 non-radio equipped trucks.",

${ }^{23}$ Docket No. II997, 22 FEd. REg. 2684 (I957).

34 This estimate is based on the total number of licensed transmitters in all private radio services (excluding the amateur radio service) of $1,003,206$ as of January $I, 1957$. (This total has been obtained from the Commission's records as yet unpublished, but it will appear in the 23d Annual Report of the FCC to be submitted to Congress in January 1958.) The average cost of a transmitter used in these private services is $\$ 500$, making the total investment of $\$ 501,703,000$. Radio investment is, of course, only a very limited economic indication of the value of radio communications, because a small amount of radio equipment investment may control the productivity of a very much larger capital investment.

${ }^{25}$ Statement by counsel in oral argument before the Federal Communications Commission sitting en bane in the rule-making proceeding in Docket No. 9703, In the Matter of Revision of Subpart $\mathrm{K}$ of Part Ir, Rules Governing the Special Industrial Radio Service, Feb. I955.

${ }^{3}$ Estimates obtained from the operating personnel of two large private radio systems operating in the oil fields of Louisiana and Texas.

${ }^{37}$ Petition of American Trucking Associations, for Modification of Eligibility Provisions of $\$ 16.30 \mathrm{r}$ of Highway Truck Radio Service Rules, Exhibit A, filed with the FCC on June 21, I95r. 
In spite of this high public interest value of private radio communications, no licensee in the rapidly growing industrial and land transportation private radio communication fields has any assurance that some other applicant in the same area will not ask for and receive the assignment of the same frequency. This happens every day to various licensees in the special industrial radio service and will continue to happen with increased frequency if the Commission's proposal to create a business radio service now pending in the proceeding in Docket IIggI is adopted. ${ }^{28}$

There are ways in which these large investments in radio communications can be protected and the needed security in the use of radio communications by private business assured. The Commission has thus far shown, however, a marked reluctance to provide any effective protection in the private radio communications field. The justification for this casual attitude toward a half a billion dollar radio equipment investment which controls the productivity of billions of dollars' worth of industrial equipment is that it would too greatly tax the administrative processes and the personnel of the Commission. The question which poses itself at this point is: Hasn't the Commission been expressly created to tackle just such difficult problems? The undeniable answer is yes.

The needed protection can be assured by means of frequency assignments based on an engineering determination by the Commission that a frequency can be used in a given area without interfering with or being interfered with by others. This would require the abandonment of the rigid frequency reservation ${ }^{29}$ now in effect for the various services and the assignment of frequencies to private users on the basis of engineering studies of each application under engineering standards similar to those used in the common-carrier field. ${ }^{30}$ It would also require greater care in the preparation of applications and frequency selection. But the result would be a license of substantial value and utility for the industries which are considered to be of high importance to the national economy. The Commission already has in the present Rules priority categories on the basis of which frequencies are allocated to specific services. These priorities are expressed in the Commission's eligibility Rules which give radio to some and withhold it from others on a class basis. It is the industries covered by such priority categories that should be entitled to receive frequency assignments on a protected basis by means of carefully engineered systems.

In principle, every applicant who considers radio communications important enough to his business to file an application with the FCC should receive an assign-

${ }^{28} 22$ FED. REg. 2593 (1957).

${ }^{20}$ Blocks of frequencies are allocated by the FCC to each service and are available, with minor exceptions, in the marine and aviation services, to all persons eligible in the given scrvice, uniformly throughout the United States. The FM example cited in note 15 stipra is a good illustration of the rigidity of such allocations. Similarly, in the land mobile service, the frequencies allocated, for example, to the forcst products radio service, although not used, let us say, in St. Louis, cannot be assigned there to a trucking concern because a trucker is eligible only in the motor carrier radio service, which has a different allocation. The fact that all motor carrier frequencies may already be assigned in St. Louis makes no difference. Such inequitable situations and inefficient use of frequencies would not arise if assignments were made on an engineering basis from the available supply of all mobile frequencies in any given locality.

${ }^{30}$ See, e.g., 47 C.F.R. $\$ 21.504$ (Supp. 1956). 
ment based on a determination by the Commission that the frequency will be useful and usable for the purposes for which intended. If, however, it proves impracticable to afford such treatment to all applicants-and the impracticability should be tested in actual operation, rather than assumed by the FCC from its past experience with large numbers of applications which are now given only a routine scrutiny-the applicants whose radio usage is deemed to be of lower priority or importance to the national economy would continue to be assigned frequencies under the procedures now in effect. The tools for devising such priority categories and processing standards are available and tested by experience: the FCC has recorded certain guiding principles developed in connection with the establishment of the various private services which, with certain modifications, could provide a starting point for a frequency-assignment procedure that would supply the needed protection to applicants in the highly important industries where radio communications have become a necessity. These are the six principles announced more than ten years ago in one of the early basic allocation rule-making proceedings which set the pattern and laid out the framework for the private radio services we have today. ${ }^{31}$ Admittedly, such method of frequency assignments would require a larger engineering staff at the FCC. But the cost of perhaps two dozen employees would be a bargain price for the increased utility of radio for all users.

IV

\section{Protest of Frequency Assignments}

Another means of protecting private radio users against the deterioration of radio

${ }^{31}$ FCC's Report of Proposed Allocations from 25,000 kc. to 30,000,000 kc., Jan. 15, I945, Docket 665I (not published in Federal Register), p. 18; see also Report and Order in Docket No. 8658 et al, 14 FED. REG. 2264 (I949), where the six principles are repeated:

"First, the Commission examined each request to determine whether the service really required the use of radio or whether wire lines werc a practicable substitute. With an acute shortage of frequencies, it would not be in the public interest to assign a portion of the spectrum to a service which could adequately and feasibly use wire lines instead of radio. The Commission's determination was not limited to technical considerations, but also took into account economic and social factors and considerations of national policy. Second, the Commission determined that all radio services should not be evaluated alike. Radio services which are necessary for the safety of life and property deserve more consideration than those services which are more in the nature of convenience or luxury.

The third principle the Commission considered was the total number of people who would probably receive bencfits from a particular service. Where other factors were equal, the Commission attempted to meet the requests of those services which proposed to render benefits to large groups of the population rather than of those services which would aid relatively small groups.

The fourth principle related to consideration of the proper place in the spectrum for the service, based upon enginecring consideration of propagation characteristics in different portions of the spectrum. Certain frequencies can be used more effectively by services requiring comparatively long range communications, while others are better suited for short range communications.

The fifth principle also pertained to assignment of each service to its proper place in the spectrum. In determining competing requests of two or more services for the same frequencies, where one or more of the services involved had already been assigned frequencies on a regular basis, the Commission gave careful consideration to the number of transmitters and receivers already in use, the investment of the industry and the public in equipment, and the cost and feasibility of converting the equipment for operation on different frequencies.

Finally, the Commission considered the necessity of achieving international standardization of maritims mobile service allocations around the international calling frequency $156.80 \mathrm{Mc} . "$ 
communications-not as effective, however, as the one discussed above, is afforded by the protest provisions of section 309(c) of the Communications Act. ${ }^{32}$ This section was adopted in 1952 to insure that if the Commission grants a license or other type of authorization without a hearing, the grant will remain subject to protest for a thirty-day period by any party in interest. ${ }^{33}$ Section 309 (c) was subsequently amended $^{34}$ to give the Commission authority, in certain cases, to designate the protested application for an oral argument in lieu of a hearing and to permit the Commission to leave the protested grant in effect not only, as formerly, when the authorization was necessary to the maintenance and conduct of an existing service, but also when the Commission affirmatively found that the public interest so required.

Until very recently, however, the Commission was, as a practical matter, inclined . to view the protest provisions of section 309 (c) as inapplicable to the private radio service field. The landmark Yellow Cab case which appeared to announce this commission view was decided early in 1953 and involved a protest by an existing licensee in the taxicab radio service against a newcomer. ${ }^{35}$ While this case did not involve the

${ }^{32} 66$ STAT. 715, 47 U.S.C. $\$ 309$ (c) (1952):

"When any instrument of authorization is granted by the Commission without a hearing as provided in subsection (a) hereof, such grant shall remain subject to protest as hereinafter provided for a pcriod of thirty days. During such thirty-day period any party in interest may file a protest under oath directed to such grant and request a hearing on said application so granted. Any protest so filed shall be scrved on the grantee, shall contain such allegations of fact as will show the protestant to be a party in interest, and shall specify with particularity the facts relied upon by the protestant as showing that the grant was improperly made or would otherwise not be in the public interest. The Commission shall, within thirty days of the filing of the protest, render a decision making findings as to the sufficiency of the protest in meeting the above requirements; and, where it so finds, shall designate the application for hearing upon issues relating to all matters specified in the protest as grounds for setting aside the grant, except with respect to such matters as to which the Commission, after affording protestant an opportunity for oral argument, finds, for reasons set forth in the decision, that, even if the facts alleged were to be proven, no grounds for setting aside the grant are presentcd. The Commission may in such decision redraft the issues urged by, the protestant in accordance with the facts or substantive matters alleged in the protest, and may also specify in such decision that the application be set for hearing upon such further issues as it may prescribe, as well as whether it is adopting as its own any of the issues resulting from the matters.specified in the protest. In any hearing subsequently held upon such application issues specified by the Commission upon its own initiative or adopted by it shall be tried in the same manner provided in subsection (b) hereof, but with respect to issues resulting from facts set forth in the protest and not adopted or specified by the Commission, on its own motion, both the burden of proceeding with the introduction of evidence and the burden of proof shall be upon the protestant. The hearing and determination of cases arising under this subsection shall be expedited by the Commission and pending hearing and decision the effective date of the Commission's action to which protest is made shall be postponed to the effective date of the Commission's decision after hearing, unless the authorization involved is necessary to the maintenance or conduct of an existing servicc, or unless the Commission affirmatively finds for reasons set forth in the decision that the public interest requires that the grant remain in effect, in which event the Commission shall authorize the applicant to utilize the facilitics or authorization in question pending the Commission's decision after hearing."

For another discussion of "protest," see Fisher, Communications Act Amendments, 1952-An Attempt to Legislate Administrative Fairness, elsewhere in this symposium.

${ }^{33}$ The term "party in interest" is defined by two leading cases, FCC v. NBC, 319 U.S. 239 (1943), which gives standing to a person who suffers electrical interference within the meaning of that case as a result of the Commission's grant; and FCC v. Sanders Bros. Radio Station, 309 U.S. 470 (1940), which gives standing to a person who suffers an economic injury as a result of the Commission's grant of an authorization.

34 70 STAT. 3, 47 U.S.C. $\$ 309$ (c) (Supp. III, 1956).

${ }^{36}$ In the Matter of Protest of the Yellow Cab Co., 9 R.R. 1228 (1953). 
use of protestant's frequency by the applicant, by refusing to recognize the protestant's standing to invoke section 309 (c), on the basis of the economic injury flowing to the protestant as a result of the grant, the Commission appears to have discouraged the filing of protests in this private radio field. The unnecessarily broad language used by the Commission in denying the protest gave an indication of the Commission's attitude towards the applicability of section 309 (c) in this field: $:^{36}$

In the Safety and Special Radio Service field such services as the Taxicab Radio Service use radio only as an incident to a primary business in which the licensee is already engaged and the frequencies allocated are available only on a shared basis by all users. The Commission is of the opinion that the economic injury which a person in the Safety and Special Radio Services might suffer because a license has been granted to a competitor does not necessarily make that person a party in interest within the meaning of Federal Communications Commission v. Sanders Bros. Radio Station, 309 U.S. 470, and create rights under section 309 (c) of the Communications Act of 1934, as amended. In the instant case the alleged injury stems primarily from the fact that the two companies are in a competing business rather than from the grant of this auxiliary radio station license. As such, it is considered to be too remote and not within the scope of either the Sanders case or section 309 (c).

That the above quotation clearly expressed the Commission's attitude at that time was substantiated by its later decision in In re Application of Royal Cab Company. ${ }^{37}$ This case, unlike the Yellow $C a b$ case, involved a protest against a grant on the same frequency as that used by the protestant. While denying the protest, the Commission nevertheless took the opportunity to explain, and in so doing to narrow down, its previous decision in the Yellow Cab case by saying that all the latter case held was "that a grant of an application for one frequency did not, necessarily, make an existing licensee on another frequency a party in interest." ${ }^{38}$ As to the case before it, the Commission based its denial of the protest on the view that the facts set out in support of the alleged economic injury failed to show that reasonable injury would flow as a result of the Commission's grant. The Commission was very careful to make clear, moreover, that its holding applied only to the facts then before it and was in no way intended to read taxicab licensees out of section 309 (c). By so doing, the Commission paved the way for overruling the Yellow Cab case doctrine at the first opportunity. And it did just that in a recent decision involving a protest by an existing taxicab company in Wichita, Kansas, against the grant of an authorization in the taxicab radio service to another cab company in the same city, but on a different frequency. ${ }^{30}$ The protestant company in this case alleged that it would suffer economic injuries which would be attributable to the fact that the applicant was enabled to employ radio communications in dispatching its cabs. Thus, the economic injury was clearly tied to the Commission's action. The Commission reluctantly recognized the protestant's standing and overruled its previous holdings in these words: ${ }^{40}$

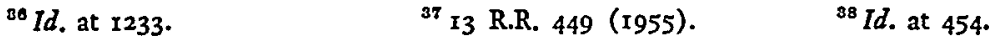

${ }^{89}$ In the Matter of Application of Best Cabs, 15 R.R. 641 (1957). ${ }^{10}$ Id. at 642.
} 
Best Cabs, Inc. cites two prior Commission cases in this field in support of its arguments that protestant has no standing under section 309 (c) to challenge its grant. (Yellow Cab Company v. Service Livery, Inc. (1953) 9 P.\&F. R.R. I22(a) and Safety Cab Company v. Royal Cab Company, I3 P.\&F. R.R. 449). But we have, on full and careful reconsideration of this question, concluded that a competitor, such as City Cabs, Inc., has standing to protest a new authorization which will cause it economic injury separate and independent from that which would result from the mere operation of a competing company. We believe this conclusion is compelled by the Sanders case ... cf. T. E. Allen and Sons, Inc., 9 P.\&F. R.R. 197).

Also, recently, the Commission, in the Lemoyne case, recognized the standing of a municipality to protest the grant of an application of another municipality for authority to operate in the fire radio service on the same frequency as that used by the protestant. $^{41}$ However, in both the Best Cabs and Lemoyne cases, the Commission allowed the protested grant to continue in effect, pending the outcome of the hearing. By so doing, the Commission has greatly weakened the value of section 309 (c) in the private radio field, although perhaps this is merely another manifestation of the Commission's reluctance to allow the full play of the protest remedy in the private radio field. As time goes on, and other cases arise, this attitude may become tempered by reconsideration, as occurred in the original harsh decision in the Yellow Cab case.

\section{The Common-Carrier Field}

In the common-carrier field, ${ }^{42}$ the existence of the problem of protecting the licensee against competition was recognized by the Commission early in the history of the two-way common-carrier mobile service and antedates section $309(\mathrm{c})$. The following passage in a rule-making proceeding ${ }^{43}$ is addressed to this problem : ${ }^{44}$

In adopting the instant decision, we do not prescribe any rule or policy to determine how many miscellaneous carriers may be authorized to operate in any given area. The exact delineation of those areas in which one or two systems might be authorized, as distinguished from those in which more than two might be required and permitted, is not a matter which is susceptible of general definition, but must rest upon a careful case-by-case - determination.

Shortly thereafter, the first occasion arose for delineating the boundaries of the protection to be afforded an existing two-way common-carrier licensee against competition from a newcomer. The case was In the Matter of Application of Martin I. Nunn. ${ }^{45}$ Mr. Nunn applied for a two-way common-carrier station in Rome, New York. The existing licensee in that city filed a letter of objection requesting that the

\footnotetext{
41 In re Application of Borough of Lemoyne, Pennsylvania, Docket No. $1 \times 945$ (not reported in Pikr \& Fischer Radio Reg.)

"2 The discussion of "common carriers" in this article covers only common carriers which are not also engaged in providing public landline message telephone service, i.e., those not connected with the telephone companies.

${ }^{8}$ In the Matter of Establishment of Policy Affecting $60 \mathrm{kc}$, Adjacent Channel Frequency Assignments for Miscellaneous Carriers, Docket No. 9648 , Oct. 18 , 1950.

14 I5 FED. Reg. 7268 (x950).

${ }^{16} 7$ R.R. 844 (195I).
} 
Nunn application be designated for a hearing to determine whether a grant thereof would serve the public interest, convenience, or necessity. The principal thrust of the objection was that the amount of two-way mobile communications business that could be generated in Rome, New York, was insufficient to support the competitiveoperations that would result from the grant of the application. The Commission granted the Nunn application, basing its action on the conclusion that the institution of a competitive service would be desirable and in the public interest in a city the size of Rome, considering the proximity of Utica, total population, 284,700. ${ }^{46}$ TheCommission also announced a broad principle, which is invariably invoked in every protest case, that competition in the two-way mobile radio field is generally desirable; but added that this approach must, of course, be tested against the facts of each case, and qualified it further by saying that, to be justified, competition should insure somebeneficial effect, e.g., improve the art, achieve better service, lower rates, etc.

With the adoption in 1952 of the protest provisions of section 309 (c), the two-way common-carrier licensee received a statutory weapon in his struggle for protection. ${ }^{47}$ Although this section of the Act has been in effect for more than five years and has been invoked many times by common-carrier licensees, the first Commission decision after a hearing delineating its area of protection in the common-carrier field is yet tobe issued. The Commission, however, has made a preliminary announcement of its approval of an examiner's initial decision in a landmark case involving a protest by an existing common-carrier operator in Bakersfield, California, against a grant without a hearing of an application by a newcomer, one Lloyd Frame, for a two-way common-carrier station in the same city. ${ }^{48}$ The existing licensee alleged that he was a party in interest because the advent of another competitor would cause a loss of revenues for his station. As a reason for denying the Frame application, the protestant alleged, in so far as here pertinent, that he was losing money; that his. station had the capacity of accommodating double the number of subscribers it was serving; that the station was prudently and efficiently operated; and that there was noneed for an additional facility in the Bakersfield area. The protest was granted, and the Frame application was designated for hearing with the effectiveness of the grant

"Whatever validity this part of the decision may have had, it seems to have been seriously weakened by the Commission's refusal to base a need for an additional service on the mere size of the city in In the Matter of the Application of New York Technical Institute of Cincinnati, 15 R.R. 892 (I957). Seepassage from the case quoted, infra p. $64 \mathrm{I}$.

${ }^{17}$ This weapon is considered to have been generally reinforced by the Supreme Court's decision in FCC v. RCA Communications, 346 U.S. 86, 97 (I953), popularly known as the Three Circuits case. Although the type of service involved in this case was different from the two-way mobile service, the Court's view as to the function of competition does not appear to be so limited:

". . . the Commission must at least warrant, as it were, that competition would serve some beneficial purpose such as maintaining good service and improving it. Although we think RCAC's contention that an applicant must demonstrate tangible benefits, is asking too much, it is not too much to ask that there be ground for reasonable expectation that competition may have some beneficial effect. Merely to assume that competition is bound to be of advantage, in an industry so regulated and so largely closed as is this one, is not enough."

${ }^{48}$ In the Matter of the Application of Lloyd Frame, 14 R.R. 637 (1956), Public Notice No. 48065, July 19, 1957, affirming the examiner's denial of the application. 
set aside, as required by section 309 (c) then in effect. ${ }^{49}$ After the hearing, the examiner issued an initial decision upholding the protest and denying the Frame application for the reason, among others, that there was no reasonable expectation that the competition incident to a second two-way common-carrier radio service would have a beneficial effect where the existing licensee, who was operating at less than half of his capacity and losing money, was rendering reasonably efficient and sufficient service and there was no contention that the applicant's service would be an improvement.

The Commission has interpreted liberally the party-in-interest phrase as used in section 309 (c) so that, as a practical matter, any existing two-way common-carrier operator can establish his standing to protest a newcomer's application and succeed in having it designated for a hearing on the basis of two allegations: (I) economic injury and (2) no need for an additional facility. ${ }^{50}$

Although an existing two-way common-carrier operator can now feel secure in his knowledge that his protest against the grant of an application of a newcomer in his area of operation will be recognized and the application designated for hearing if he meets the formal protest requirements of section 309 (c), the 1956 amendment to that section erected a new obstacle in his fight to protect his investment and business future. The culprit is the provision of the amendment which abolished the previous mandatory requirement to set aside the effectiveness of the grant when allowing a protest against it, and vested in the Commission discretionary power to leave the protested grant in effect if it is shown that the public interest so requires. With the advent of this amendment, the existing licensee must, in addition to establishing his standing to protest, show that the effectiveness of the protested grant should be suspended. Unless he succeeds in having the grant suspended pending the outcome of the protest hearing, the harm against which he seeks protection may come to pass before the final decision is wrung out of the legal machinery of the FCC. ${ }^{51}$ It is not

${ }^{99}$ The protest was granted prior to the enactment of the 1956 amendment to $\$ 309(\mathrm{c})$, 70 STAT. 3, 47 U.S.C. $\$ 309$ (c) (Supp. III, 1956).

5o This has been assured by the Commission's disposition of an attack on the validity of a protest in the case of In the Matter of Application of Bell Telephone Co. of Pennsylvania, 12 R.R. 1409 (1955):

"In alleging that the grant to Bell (Applicant) will result in ruinous competition, and that there is no need for an additional service in the area involved, Law (Protestant) has presented allegations which suffice, in a case involving communications common carriers, to afford him both standing to protest and a basis for hearing under the provisions of $\$ 309$ (c) of our Act."

Any attempt by the Commission to restrict the standing to protest based on economic injury would, of course, be contrary to the interpretation placed upon $\S 309$ (c) by the court in Clarksburg Publishing Co. v. FCC, 225 F.2d 5 II (D.C. Cir. 1955).

${ }^{51}$ The Commission is under a mandate to expedite all protest hearings, and every effort is made to do so; however, it still takes approximately $r 8$ months, sometimes longer, before a final decision after a hearing is issued. This delay is the normal result of the procedural steps which are vouchsafed to the parties: after the evidentiary hearing is completed, the parties are given an opportunity to file findings of fact and conclusions; then the hearing examiner issues his initial decision; the latter is subject to exceptions and a request for an oral argument before the Commission en banc, which is a matter of right, if duly requested, and it is requested in virtually all protest cases by the losing party. After the oral argument, the Commission takes the case under consideration and issucs its final decision. All things considered, an $\mathrm{r} 8$-month period between the designation of an application for a hearing and final decision does not appear to be an unduly long one, in the circumstances. 
inconceivable that an operator in a precarious financial position could succumb as a result of the newcomer's competition before the hearing was concluded.

This point was sharply raised in a recent case involving an applicant in Clearwater, Florida, whose application was protested by an existing operator in nearby St. Petersburg. ${ }^{62}$ In this case, a portion of the applicant's protected service contour lay outside the service contour of the protesting St. Petersburg station. In addition, the applicant was able to show that there was actual need and demand for the new service in the nonoverlap area. The Commission recognized that this was the type of situation in which it could properly exercise its discretionary power granted by the $195^{6}$ amendment to section 309 (c) and leave the protested grant in effect pending the outcome of the hearing; and the Commission did so. ${ }^{53}$ Thus, the Commission appears to have established the principle that the protested grant of a two-way common-carrier facility will be allowed to remain in effect if it is shown that the new service will supply an actual need that cannot be met by the existing operator. In practice, such need must be outside the protected contour of the existing operator's station, because if it were inside and if the existing operator had sufficient excess capacity to meet it, it would be virtually impossible to show that he could not meet it. $^{\text {}}$ This principle appears to have been reinforced by the Commission in a still more recent case involving a proposed station in Detroit. ${ }^{55}$ In this case, the applicant sought to base its claim for allowing its grant to remain in effect, pending final decision after a hearing, on the fact that Detroit is a very large city and that from this very size, the Commission should assume a need for an additional (in this case, third) station. The Commission denied this request and suspended the effectiveness of the grant in these words: ${ }^{56}$

The service area lying outside Protestant's $37 \mathrm{dbu}$ contour does not appear to be too substantial (including the area in Canada to which service is, of course, not rendered)see Fig. I, attached to Applicant's Opposition To Protest. But our disposition of Applicant's request that the effective date of its grant be not postponed does not rest on the

${ }^{82}$ In the Matter of Application of Moon Electric Co., 15 R.R. 56(d) (1957).

${ }^{69} \mathrm{Yd}$. at $6 \mathrm{x}$. The Commission made the following finding in support of allowing the grant to remain in effect:

"The subject grant involves a common carrier facility which serves the public for hire. ... In this case, the really significant point is that the applicant proposes to serve a substantial area, which has no reliable coverage (as that term is defined in $\$ 21.504$ of our Rules). There is apparently no dispute that some of Applicant's service area falls outside Protestant's $37 \mathrm{dbu}$ contour. Applicant has demonstrated an apparent prima facie public need for his service in the area to the north of Clearwater, all or some of which is outside Protestant's $37 \mathrm{dbu}$ coverage, and now has public subscribers who assert (see Applicant's response to protest) that they need Applicant's service and depend thereon for the conduct of their business in that area. In the light of these circumstances, we find and conclude, for the limited purposes of determining whether or not to terminate Applicant's grant at this time, and subject to final determination upon the hearing record herein, that the public interest requires that the grant herein remain in effect pending our decision after hearing, and we authorize the Applicant to continue the rendition of service tests pending that event."

${ }^{04}$ Nor is the applicant's case any better if, as often happens, he can show that the prospective customers prefer his services to the existing one, since such personal preference is irrelevant, in view of the common carrier's obligation to render service upon a reasonable demand.

${ }^{65}$ In the Matter of the Application of New York Technical Institute of Cincinnati, I5 R.R. 892 (1957).

so Ibid. 
size of the area served by Protestant or on the validity of Protestant's allegation as to service by the other existing operator in Detroit (see paragraph 6 above). The crucial consideration is the need for Applicant's new service in the area falling outside Protestant's $37 \mathrm{dbu}$ contour. Applicant's claim that there is such a need is not related to the area in question but rather is based upon the population and business statistics for the whole Detroit area. Applicant infers that the need for its service is spread uniformly throughout the entire Detroit area and, therefore, it can be assumed that, since Protestant does not provide service in particular areas, there is an unfulfilled need for service in these areas which Applicant can and will provide. Applicant has not related any statistics, or offered any specific facts tending to show a need for service in the particular areas in which it claims it will be the sole purveyor of service. In the light of these circumstances, we find and conclude, for the limited purposes of determining whether or not to terminate Applicant's grant at this time, that no affrmative showing has been made that the public interest requires that the grant remain in effect pending our decision after hearing. In this respect, this case differs markedly from the Moon Electric Company case, 15 R.R. $56(d)$.

This lays down a sound principle and constitutes a salutary departure from the apparent rationale of the $N u n n$ case, that the need for a competing station could be inferred from the size of the city to be served, without more.

\section{VI}

\section{CoNCLUSIONS}

In summary, there are hopeful signs on the horizon that the FCC may be moving toward recognizing as legitimate the pressing needs of all segments of industry for more frequencies for mobile communication use. The initial needs of those eligible under the existing regulations may be temporarily met by such technical devices as the reductions in channel separations permitted by the advances in the radio art. But so long as such grants of additional frequencies are accompanied by an undue relaxation of the existing eligibility standards, the FCC will be taking one step forward and moving two steps back. The need for more frequencies must be met boldly by taking a critical look at those services which have failed to use the space allocated to them. This must be accompanied by a meaningful measure of protection for existing mobile licensees. Steps to achieve such protection should be taken now, while all possibilities for new frequency sources are earnestly explored, lest the full development of mobile communications be stifled.

Section 309 (c) can become an effective means of protection in the private radio field. As the importance of mobile radio communications becomes recognized there is no reason why a company which had the foresight to apply for a radio license when this art was still new should not be entitled to a preference over a late-comer. The principle that every person is entitled to a mobile radio license, no matter what the consequences for other licensees, since, for the sake of administrative convenience, the frequencies are allocated on a shared basis, is not only unsound, but also selfdefeating. For the end result would see everyone with radio, but no one able to use it effectively. Communications for all may easily become communications for none. 
From the very beginning, first come, first served has been the order of things in the broadcast field, and no one seriously contends that the results are inequitable. So in the private mobile radio field, as long as the supply of frequencies is limited, the licensee with a substantial radio equipment investment used in an important business operation where mobile radio communications are indispensable to the safety and efficiency of the enterprise should be given a protected frequency assignment through appropriate rule provision and/or under the protest procedure of section 309 (c). A denial of a license on the same frequency to a newcomer whose use destroys or materially deteriorates the usage of the first licensee would seem to be entirely justified.

In the common-carrier field, the following principles would be consistent with the rationale of the decided cases: No competing mobile facility should be authorized in any area served by an existing carrier or carriers whenever the evidence shows that (I) the existing facility is managed efficiently, (2) it has excess capacity, and (3) the operator is losing money or is not making an unreasonably high rate of return on his investment. When these conditions are shown to exist, it could hardly be found that competition would have any beneficial effect. ${ }^{57}$ To put it differently, the existence of these three conditions should constitute a conclusive presumption that there is no need for an additional mobile common carrier in the area.

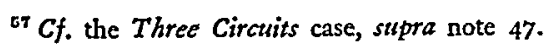

